\title{
21-O-Angeloyltheasapogenol E3, a Novel Triterpenoid Saponin from the Seeds of Tea Plants, Inhibits Macrophage-Mediated Inflammatory Responses in a NF- $\kappa$ B-Dependent Manner
}

\author{
Woo Seok Yang, ${ }^{1}$ Jaeyoung Ko, ${ }^{2}$ Eunji Kim, ${ }^{1}$ Ji Hye Kim, ${ }^{1}$ \\ Jae Gwang Park, ${ }^{1}$ Nak Yoon Sung, ${ }^{1}$ Han Gyung Kim, ${ }^{1}$ Sungjae Yang, ${ }^{1}$ Ho Sik Rho, ${ }^{2}$ \\ Yong Deog Hong, ${ }^{2}$ Song Seok Shin, ${ }^{2}$ and Jae Youl Cho ${ }^{1}$ \\ ${ }^{1}$ Department of Genetic Engineering, Sungkyunkwan University, Suwon 440-746, Republic of Korea \\ ${ }^{2}$ Medical Beauty Research Institute, AmorePacific R\&D Center, Yongin 446-729, Republic of Korea
}

Correspondence should be addressed to Song Seok Shin; ssshin@amorepacific.com and Jae Youl Cho; jaecho@skku.edu

Received 27 July 2014; Revised 2 October 2014; Accepted 3 October 2014; Published 10 November 2014

Academic Editor: Tânia Silvia Fröde

Copyright (C) 2014 Woo Seok Yang et al. This is an open access article distributed under the Creative Commons Attribution License, which permits unrestricted use, distribution, and reproduction in any medium, provided the original work is properly cited.

\begin{abstract}
21-O-Angeloyltheasapogenol E3 (ATS-E3) is a triterpenoid saponin recently isolated from the seeds of the tea tree Camellia sinensis (L.) O. Kuntze. ATS-E3 has several beneficial properties including anti-inflammatory, antidiabetic, antiatherosclerotic, and anticancer effects. Unlike other phenolic compounds isolated from tea plants, there are no studies reporting the pharmacological action of ATS-E3. In this study, we therefore aimed to explore the cellular and molecular inhibitory activities of ATS-E3 in macrophage-mediated inflammatory responses. ATS-E3 remarkably diminished cellular responses of macrophages such as FITCdextran-induced phagocytic uptake, sodium nitroprusside- (SNP-) induced radical generation, and LPS-induced nitric oxide (NO) production. Analysis of its molecular activity showed that this compound significantly suppressed the expression of inducible NO synthase (iNOS), nuclear translocation of nuclear factor- (NF-) $\kappa \mathrm{B}$ subunits (p50 and p65), phosphorylation of inhibitor of $\kappa \mathrm{B}$ kinase (IKK), and the enzyme activity of AKT1. Taken together, the novel triterpenoid saponin compound ATS-E3 contributes to the beneficial effects of tea plants by exerting anti-inflammatory and antioxidative activities in an AKT/IKK/NF- $\kappa \mathrm{B}$-dependent manner.
\end{abstract}

\section{Introduction}

Macrophages are representative immune cells regulating the inflammatory barrier, an important defensive system against infecting pathogens such as bacteria, viruses, and fungi $[1,2]$. To produce their inflammatory responses, these cells use special surface receptors (e.g., toll-like receptors (TLRs)) that are involved in recognizing biomaterials derived from pathogens and act as central molecules for managing macrophage functions during immunopathological processes. The activation of these receptors also transduces a variety of intracellular signaling cascades composed of phosphatidylinositide 3-kinase (PI3K), phosphoinositide-dependent kinase-1 (PDK1), AKT, inhibitor of $\kappa \mathrm{B}(\mathrm{I} \kappa \mathrm{B})$ kinase (IKK), and $\mathrm{I} \kappa \mathrm{B} \alpha$. These signaling pathways are linked to the nuclear translocation of transcription factors such as nuclear factor- (NF-) $\kappa \mathrm{B}$ to synthesize new inflammation-regulatory genes such as cytokines and chemokines. At the same time, macrophages produce a large number of toxic chemicals such as nitric oxide (NO) and reactive oxygen species (ROS) to directly attack and phagocytose infected pathogens in order to decrease the numbers of infected microorganisms. Although the macrophage-mediated inflammatory barrier is a useful biological event, functions that are overactivated by these cells can cause additional pathophysiological phenomena leading to immunological diseases. Prolonged inflammatory responses by macrophages are reported to induce loss of function in certain tissues or organs, leading to serious 


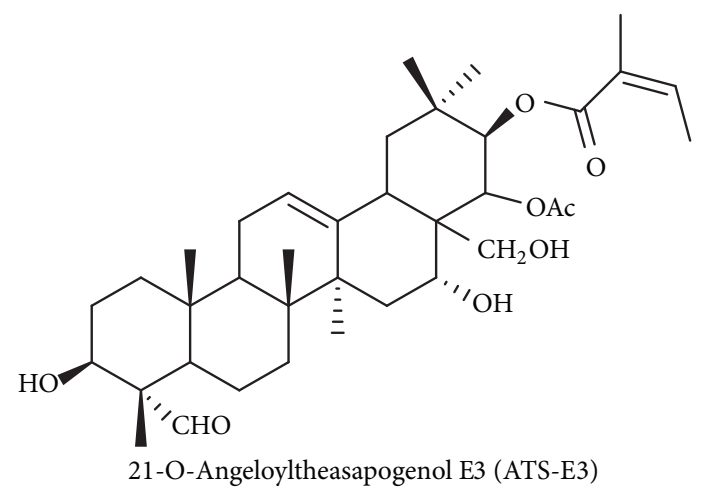

FIgURE 1: Chemical structure of ATS-E3.

diseases including cancer, atherosclerosis, autoimmune diseases, and Alzheimer's disease. Therefore, suppression of acute or chronic inflammation is regarded as an acceptable therapeutic approach for the purpose of prevention or amelioration of diseases [3-7].

To date, more than 1,800 papers have been published on tea plants (Camellia sinensis (L.) O. Kuntze), since tea is a very popular beverage with high levels of phenolic compounds. Unlike coffee, most studies on tea pharmacology have stressed the beneficial roles of these plants including neuroprotective, hepatoprotective, antioxidative, antidiabetic, anticancer, antiobesity, antibacterial, anticardiovascular, antilipogenic, and antiaging activities. Such desirable activities have led scientists to study active components producing these various pharmacological activities. Consequently, numerous chemicals such as catechins, theaflavins, tannins, and flavonoids have been identified from the leaves, seeds, or roots of tea trees. Previous reports suggest that polyphenolic compounds may be pharmacologically valuable components. In contrast, only a few papers have been published on triterpenoid saponins from tea plants. The pharmacological effects of olean-12-ene-type triterpenoid saponins from the roots of tea plants are unknown [8]. Oleiferasaponin $A_{1}$, which has antiapoptotic activity, has been isolated from the tea seed pomace (Camellia oleifera Abel) [9]. Considering that saponin fractions from Panax ginseng and Codonopsis lanceolata have been proposed as nontoxic anti-inflammatory remedy and cosmetic sources, we also aimed to isolate triterpenoid saponins with antiinflammatory properties. Therefore, in this study, we report a novel triterpenoid saponin, 21-O-angeloyltheasapogenol E3 (ATS-E3), (Figure 1) isolated from tea plant seeds and its antiinflammatory activity in macrophage-mediated inflammatory responses.

\section{Materials and Methods}

2.1. Materials. Sodium nitroprusside (SNP), 3-(4,5-dimethylthiazol-2-yl)-2,5-diphenyltetrazolium bromide (MTT), dihydrorhodamine 123 (DHR123), fluorescein isothiocyanate(FITC-) dextran, N $\omega$-nitro-L-arginine methyl ester (LNAME), and lipopolysaccharide (LPS; E. coli 0111:B4) were purchased from Sigma Chemical Co. (St. Louis, MO,
USA). BAY11-7082 (BAY), LY294002, and wortmannin were obtained from Calbiochem (La Jolla, CA, USA). Fetal bovine serum and RPMI 1640 were obtained from Gibco (Grand Island, NY, USA). The murine macrophage cell line RAW264.7 and human embryonic kidney (HEK) 293 cells were purchased from the American Type Culture Collection (Rockville, MD, USA). All other chemicals were of analytical grade and were obtained from Sigma. A luciferase construct containing binding sites for NF- $\kappa \mathrm{B}$ was a gift from Professor Hae Young Chung (Pusan National University, Pusan, Korea). DNA constructs with FLAG-MyD88 and Myc-Syk were used as reported previously [10]. Phosphospecific and/or total antibodies against NF- $\kappa \mathrm{B}$ subunits (p50 and p65), I $\kappa \mathrm{B} \alpha, \mathrm{IKK}$, $\mathrm{AKT}, \mathrm{PDK} 1$, lamin $\mathrm{A} / \mathrm{C}$, and $\beta$-actin were obtained from Cell Signaling (Beverly, MA, USA).

2.2. Preparation of 21-O-Angeloyltheasapogenol E3. 21-OAngeloyltheasapogenol E3 (ATS-E3) was prepared from the ethanolic extract of the seeds of tea plants. The extract was partitioned between ethyl acetate and distilled water, and then the ethyl acetate layer was dried to yield the ethyl acetate fraction. ATS-E3 was purified from the ethyl acetate fraction using MPLC (under a hexane-ethyl acetate solvent gradient) and was isolated as a white solid. Its physicochemical and spectroscopic data (see supplementary Figures 1 and 2 in Supplementary Material available online at http://dx.doi.org/10.1155/2014/658351) were the same as those of published values [11-13]. The seeds of tea plants used in this study were obtained from Cheju Island in Korea.

2.3. Cell Culture. RAW264.7 and HEK293 cells were cultured in RPMI 1640 medium supplemented with 10\% heatinactivated fetal bovine serum (FBS; Gibco, Grand Island, NY, USA), glutamine, and antibiotics (penicillin and streptomycin) at $37^{\circ} \mathrm{C}$ under $5 \% \mathrm{CO}_{2}$. For each experiment, the cells were detached with a cell scraper. When the cells were cultured for the experiments at a density of $2 \times 10^{6}$ cells $/ \mathrm{mL}$, the proportion of dead cells was less than $1 \%$ as determined by Trypan blue dye exclusion.

2.4. Determination of Phagocytic Uptake. To measure the phagocytic activity of RAW264.7 cells, we modified a previously reported method [14]. RAW264.7 cells $\left(5 \times 10^{4}\right)$ were pretreated with ATS-E3 (0 to $10 \mu \mathrm{M}$ ) or BAY11-7082 (10 and $15 \mu \mathrm{M})$ for $1 \mathrm{~h}$ and then resuspended in $100 \mu \mathrm{L}$ phosphatebuffered saline (PBS) containing $1 \%$ human $\mathrm{AB}$ serum and incubated with FITC-dextran $(1 \mathrm{mg} / \mathrm{mL})$ at $37^{\circ} \mathrm{C}$ for $20 \mathrm{~min}$. The reactions were stopped by adding $2 \mathrm{~mL}$ of ice-cold PBS containing $1 \%$ human serum and $0.02 \%$ sodium azide. The cells were then washed three times with cold PBS-azide and analyzed on a FACScan flow cytometer (Becton-Dickinson, San Jose, CA, USA) as reported previously [15].

2.5. Determination of Reactive Oxygen Species Generation. The level of intracellular ROS was determined by recording the change in fluorescence resulting from the oxidation of the fluorescent probe DHR123. Briefly, $5 \times 10^{5}$ RAW264.7 cells were exposed to ATS-E3 (0 to $10 \mu \mathrm{M}$ ) for $30 \mathrm{~min}$ and then incubated with SNP $(0.25 \mathrm{mM})$ at $37^{\circ} \mathrm{C}$ for $20 \mathrm{~min}$ to 
induce ROS production. The cells were further incubated with $20 \mu \mathrm{M}$ of the fluorescent probe DHR123 for $30 \mathrm{~min}$ at $37^{\circ} \mathrm{C}$. The degree of fluorescence, which corresponded to the level of intracellular ROS, was determined using a FACScan flow cytometer (Becton-Dickinson) as reported previously [15].

2.6. Flow Cytometric Analysis. The level of FITC-dextran or ROS in RAW264.7 cells was determined by flow cytometric analysis $[16,17]$. RAW264.7 cells $\left(2 \times 10^{6}\right.$ cells $\left./ \mathrm{mL}\right)$ treated with AP736 in the presence or absence of FITC-dextran $(1 \mathrm{mg} / \mathrm{mL})$ or DHR123 were washed with staining buffer containing $2 \%$ rabbit serum and $1 \%$ sodium azide in PBS and incubated with directly labeled antibodies for an additional $45 \mathrm{~min}$ on ice. After washing three times with staining buffer, stained cells were analyzed on a FACScan flow cytometer (Becton-Dickinson).

2.7. NO Production. RAW264.7 macrophage cells $(1 \times$ $10^{6}$ cells $\left./ \mathrm{mL}\right)$ were cultured for $18 \mathrm{~h}$, pretreated with ATSE3 $(0$ to $10 \mu \mathrm{M})$ for $30 \mathrm{~min}$, and further incubated with LPS $(1 \mu \mathrm{g} / \mathrm{mL})$ for $24 \mathrm{~h}$. The inhibitory effect of ATS-E3 on LPSinduced NO production was determined by analyzing NO level using Griess reagent as previously described [18, 19]. The $\mathrm{OD}$ at $550 \mathrm{~nm}\left(\mathrm{OD}_{550}\right)$ was measured using a SpectraMax 250 microplate reader (Molecular Devices, Sunnyvale, CA, USA).

2.8. Cell Viability Test. RAW264.7 cells $\left(1 \times 10^{6}\right.$ cells $\left./ \mathrm{mL}\right)$ were cultured for $18 \mathrm{~h}$, after which ATS-E3 ( 0 to $10 \mu \mathrm{M})$ was added to the cells for the final 24 or $8 \mathrm{~h}$ of culture, respectively. The cytotoxic effect of ATS-E3 was then evaluated by a conventional MTT assay as reported previously [20, 21]. For the final $3 \mathrm{~h}$ of culture, $10 \mu \mathrm{L}$ MTT solution $(10 \mathrm{mg} / \mathrm{mL}$ in PBS, $\mathrm{pH}$ 7.4) was added to each well. The incubation was stopped by the addition of $15 \%$ sodium dodecyl sulfate (SDS) into each well, which solubilized the formazan [22]. The absorbance at $570 \mathrm{~nm}\left(\mathrm{OD}_{570-630}\right)$ was measured using a SpectraMax 250 microplate reader (BioTek, Bad Friedrichshall, Germany).

2.9. Analysis of iNOS Expression by Real-Time Reverse Transcription-Polymerase Chain Reaction. RAW264.7 cells (1 $\times 10^{6}$ cells $\left./ \mathrm{mL}\right)$ were cultured for $18 \mathrm{~h}$, pretreated with ATSE3 $(0$ to $10 \mu \mathrm{M})$ for $30 \mathrm{~min}$, and further cultured with LPS $(1 \mu \mathrm{g} / \mathrm{mL})$ for $6 \mathrm{~h}$. The inhibitory effect of ATS-E3 on the expression of iNOS was determined by real-time quantitative reverse transcription-polymerase chain reaction (qRT-PCR) $[18,23]$. To determine the level of iNOS gene expression, total RNA was isolated from LPS-treated RAW264.7 cells using TRIzol Reagent (Gibco BRL) according to the manufacturer's instructions. The total RNA was stored at $-70^{\circ} \mathrm{C}$ until use. Real-time qRT-PCR was performed as reported previously $[24,25]$. The primers (Bioneer, Daejeon, Korea) used in these reactions are listed in Table 1.

2.10. Plasmid Transfection and Luciferase Reporter Gene Activity Assay. HEK293 cells $\left(1 \times 10^{6}\right.$ cells $\left./ \mathrm{mL}\right)$ were transfected with $1 \mu \mathrm{g}$ of plasmids driving the expression of $\beta$ galactosidase and either NF- $\kappa \mathrm{B}$-Luc or AP-1-Luc in the presence or absence of an inducing molecule MyD88 or tyrosine
TABLE 1: Primer sequences used for real-time PCR analysis.

\begin{tabular}{lll}
\hline Name & & Sequence $\left(5^{\prime}\right.$ to $\left.3^{\prime}\right)$ \\
\hline \multirow{2}{*}{ iNOS } & F & CCCTTCCGAAGTTCTGGCAGCAG \\
& R & GGCTGTCAGAGCCTCGTGGCTTTGG \\
\multirow{2}{*}{ GAPDH } & F & CACTCACGGCAAATTCAACGGCA \\
& R & GACTCCACGACATACTCAGCAC \\
\hline
\end{tabular}

kinase Myc-Syk. Transfections were performed using the PEI method in 12-well plates as previously outlined [26, 27]. Transfected cells were used at $48 \mathrm{~h}$ posttransfection for all experiments. Cells were treated with ATS-E3 for the final $8 \mathrm{~h}$ of each experiment. Luciferase assays were performed using the Luciferase Assay System (Promega, Madison, WI), as previously reported [28].

2.11. Preparation of Cell Lysates and Immunoblotting Analysis. RAW264.7 cells $\left(5 \times 10^{6}\right.$ cells $\left./ \mathrm{mL}\right)$ were washed three times in cold PBS supplemented with $1 \mathrm{mM}$ sodium orthovanadate, resuspended in lysis buffer $(20 \mathrm{mM}$ Tris- $\mathrm{HCl}$, $\mathrm{pH}$ 7.4, $2 \mathrm{mM}$ EDTA, $2 \mathrm{mM}$ ethyleneglycotetraacetic acid, $50 \mathrm{mM} \beta$-glycerophosphate, $1 \mathrm{mM}$ sodium orthovanadate, $1 \mathrm{mM}$ dithiothreitol, $1 \%$ Triton X-100, 10\% glycerol, $10 \mu \mathrm{g} / \mathrm{mL}$ aprotinin, $10 \mu \mathrm{g} / \mathrm{mL}$ pepstatin, $1 \mathrm{mM}$ benzamide, and $2 \mathrm{mM}$ PMSF), lysed by sonication, and rotated for $30 \mathrm{~min}$ at $4^{\circ} \mathrm{C}$. The lysates were clarified by centrifugation at $16,000 \times \mathrm{g}$ for $10 \mathrm{~min}$ at $4^{\circ} \mathrm{C}$ and stored at $-20^{\circ} \mathrm{C}$ until use. The soluble fractions of the cell lysates were immunoblotted, and total and phosphoprotein levels of p50, p65, I $\kappa \mathrm{B} \alpha, \mathrm{IKK}, \mathrm{AKT}$, $\mathrm{PDK} 1$, lamin $\mathrm{A} / \mathrm{C}$, and $\beta$-actin were visualized as previously reported [29].

2.12. PDK1 and AKT1 Kinase Assay. To evaluate the ability of ATS-E3 to inhibit the activity of purified PDK1 and AKT1, we used the Millipore Kinase Profiler service (Billerica, MA, USA) as reported previously [30]. Human PDK1 or AKT1 (1$5 \mathrm{mU}$ ) was incubated in reaction buffer in a final reaction volume of $25 \mu \mathrm{L}$. The reaction was initiated by the addition of MgATP. After incubation for $40 \mathrm{~min}$ at room temperature, the reaction was stopped by the addition of $5 \mathrm{~mL}$ of a $3 \%$ phosphoric acid solution. The reaction product $(10 \mu \mathrm{L})$ was spotted onto a P30 Filtermat and washed three times for $5 \mathrm{~min}$ each with $75 \mathrm{mM}$ phosphoric acid and once in methanol prior to drying and scintillation counting.

2.13. Statistical Analysis. Data are expressed as the mean \pm standard deviation (SD), as calculated from one $(n=6)$ of two independent experiments. Other data are representative of three different experiments with similar results. For statistical comparisons, the results were analyzed using analysis of variance/Scheffe's post-hoc test and the Kruskal-Wallis/MannWhitney test. A $P$ value $<0.05$ was considered to be statistically significant. All statistical tests were conducted using SPSS (SPSS Inc., Chicago, IL, USA).

\section{Results and Discussion}

No previous studies have reported the biological activity of ATS-E3, a novel triterpenoid saponin isolated from Camellia 


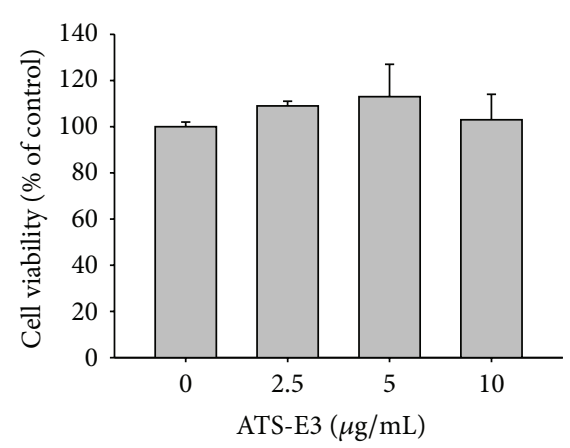

(a)

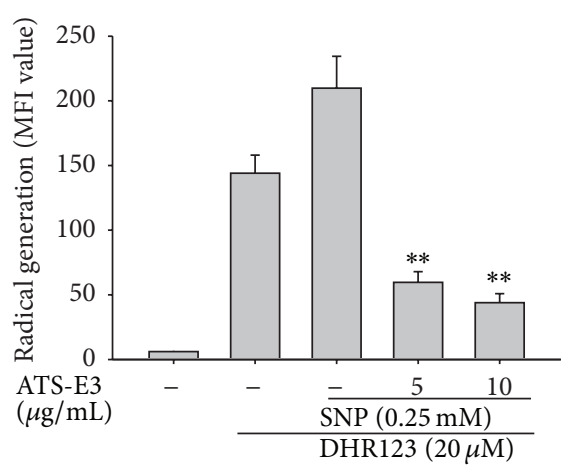

(c)
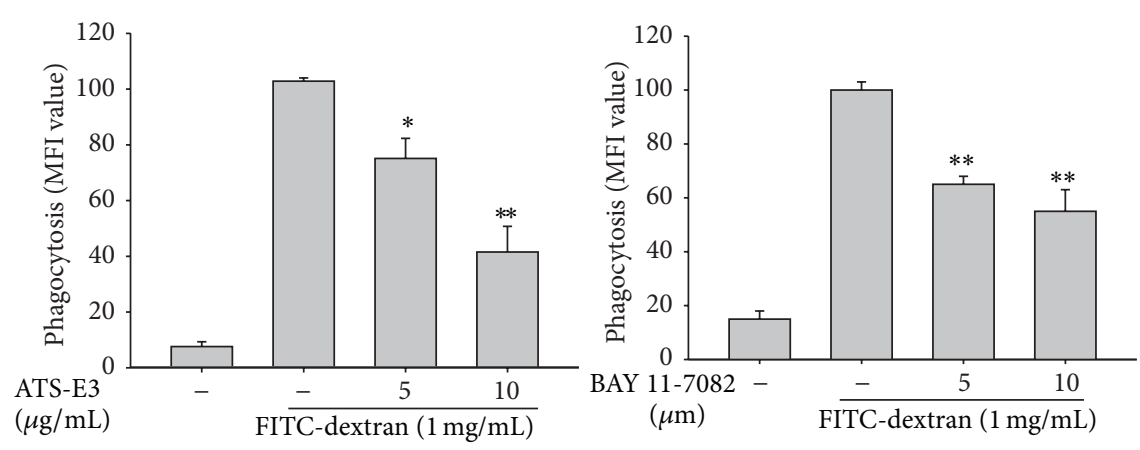

(b)
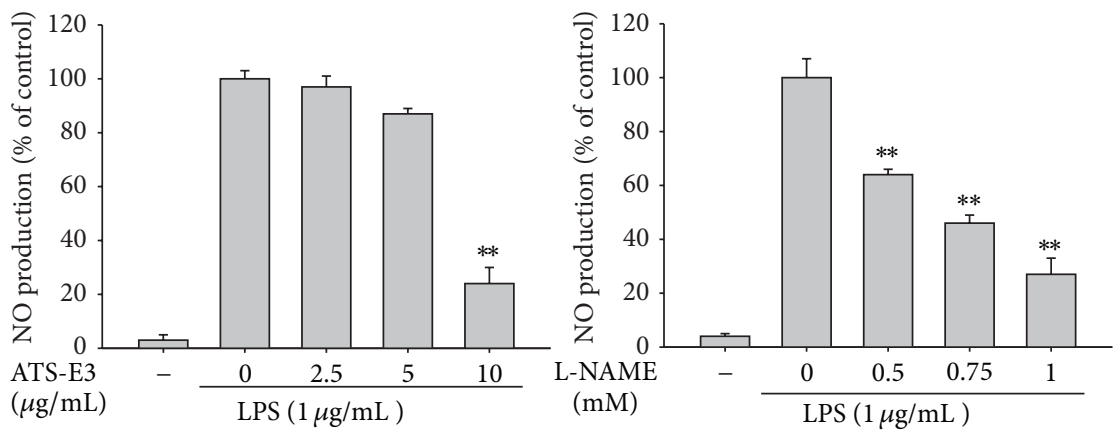

(d)

FIGURE 2: The effects of ATS-E3 on macrophage-mediated inflammatory responses. (a) RAW264.7 cells $\left(1 \times 10^{6}\right.$ cells $\left./ \mathrm{mL}\right)$ were treated with ATS-E3 for 6 or $24 \mathrm{~h}$. Cell viability was evaluated using the MTT assay. (b) RAW264.7 cells preincubated with ATS-E3 (left panel) or BAY117082 (right panel) were treated with FITC-dextran $(1 \mathrm{mg} / \mathrm{mL})$ for $2 \mathrm{~h}$. The level of dextran uptake was determined by flow cytometric analysis. (c) Scavenging effect of ATS-E3 on reactive oxygen species (ROS) generation in sodium nitroprusside- (SNP-) treated RAW264.7 cells was examined by flow cytometric analysis using DHR123 $(20 \mu \mathrm{M})$ and SNP $(0.25 \mathrm{mM})$. (d) NO inhibitory activities of ATS-E3 (left panel) or LNAME (right panel) were determined with RAW264.7 cells $\left(1 \times 10^{6}\right.$ cells $\left./ \mathrm{mL}\right)$ treated with LPS $(1 \mu \mathrm{g} / \mathrm{mL})$ in the presence or absence of ATS-E3 or L-NAME for $24 \mathrm{~h}$. The cell culture supernatants were collected, and the concentrations of NO in the supernatants were determined using the Griess assay. ${ }^{*} P<0.05$ and ${ }^{* *} P<0.01$ compared to control group.

sinensis; therefore, we aimed to evaluate its pharmacological activity under macrophage-mediated inflammatory conditions. To start this study, we first examined the cytotoxic activity of ATS-E3 in macrophage-like RAW264.7 cells. As Figure 2(a) shows, there was no significant toxic effect affecting cell viability under the treatment of this compound up to $10 \mu \mathrm{M}$, indicating that the activity of ATS-E3 at 0 to $10 \mu \mathrm{M}$ concentration ranges could be due to its specific pharmacological activities.

During innate immune responses, the primary function of macrophages is to phagocytose infected or exogenous materials. Such phagocytic ability can be easily mimicked with macromolecules labeled with FITC. In fact, FITCdextran showed a 10-fold increase in RAW264.7 macrophagelike cells (Figure 2(b)), as assessed by flow cytometric analysis in a previous report [31]. Interestingly, ATS-E3 blocked phagocytosis of FITC-dextran in a dose-dependent manner (Figure 2(b), left panel). Moreover, the IKK inhibitor BAY 11-7082 also significantly diminished the uptake of FITCdextran, indicating that phagocytosis of FITC-dextran by macrophages is dependent on IKK/NF- $\kappa$ B (Figure 2(b), right panel), as reported previously [32]. Additional functions of macrophages include the release of large amounts of toxic molecules such as ROS and RNS, which cause cellular damage in tissues or organs and lead to loss of function due to inflammation [33]. Therefore, we next examined whether ATS-E3 could neutralize toxic molecules by using the radical generator SNP. To produce antioxidative activity under cellular conditions, we also used RAW264.7 cells treated with SNP. As shown in Figure 2(c), this compound completely neutralized the generated radicals. Since triterpenoid saponins such as parkioside B from the root bark of Butyrospermum parkii [34], 3 $\beta$-O- $\alpha$-l-arabinopyranosyl-19 $\alpha, 23$-dihydroxy$20 \alpha$-urs-12-en-28-oic acid $28-\mathrm{O}-\beta$-d-glucopyranosyl ester from the aerial parts of Ilex cornuta [35], and 3 3 -hydroxy23-oxo-30-noroleana-12,20(29)-diene-28-oic acid 3-O- $\beta$-Dglucuronopyranosyl-28-O- $\beta$-D-glucopyranoside from Salicornia herbacea [36] display strong antioxidative activity, the scavenging action of ATS-E3 may be due to their phytochemical properties. Therefore, these results imply that ATS-E3 can downregulate phagocytosis and prevent the generation of radicals mediated by the functional activation of macrophages.

The fact that the IKK/NF- $\kappa$ B inhibitor BAY suppressed FITC-dextran-induced phagocytosis in RAW264.7 cells (Figure 2(b), right panel) led us to hypothesize that ATS-E3 


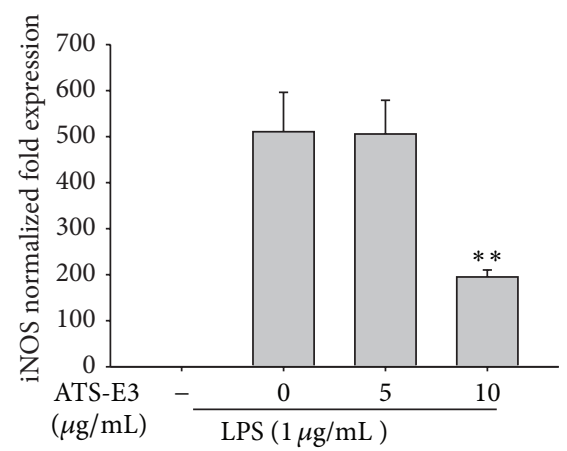

(a)

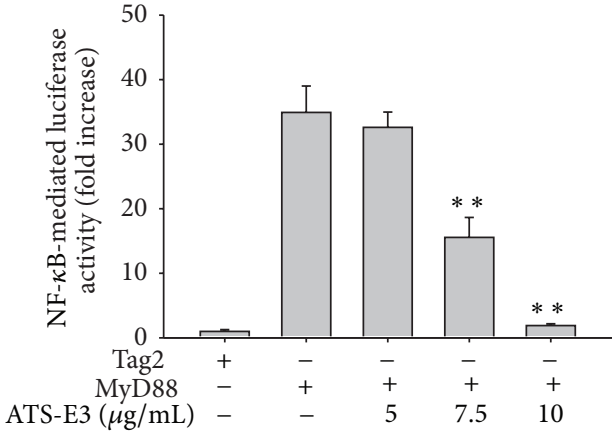

(b)

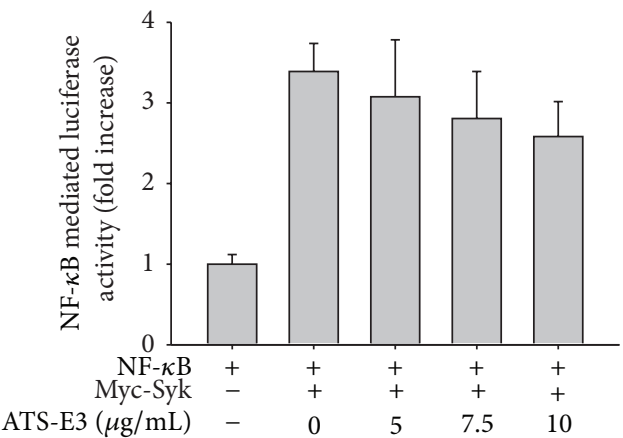

(c)

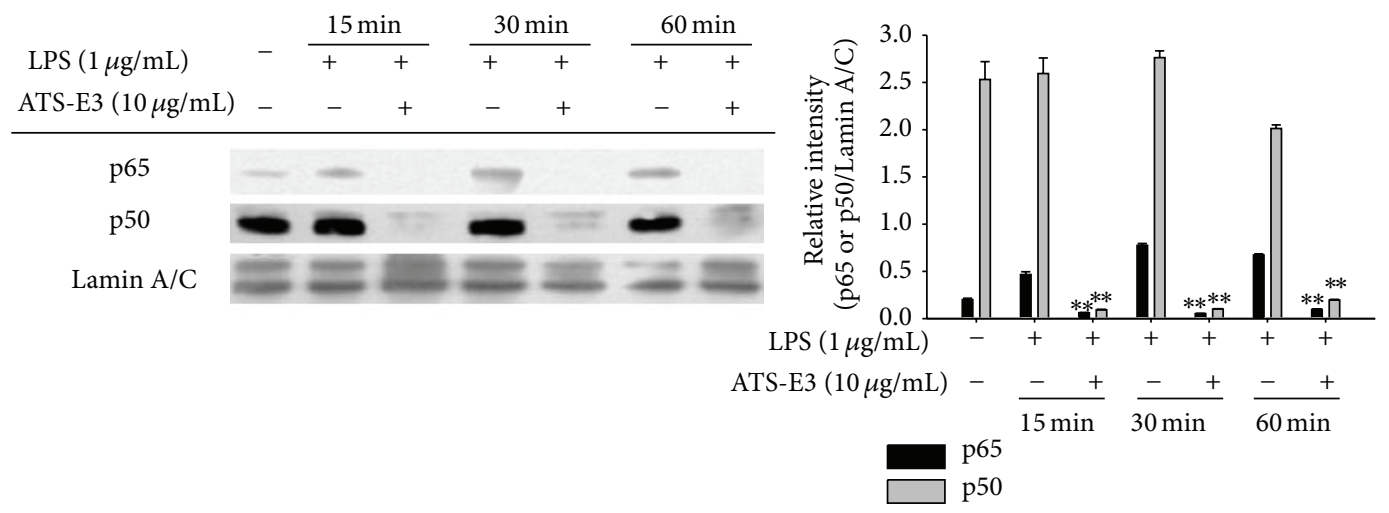

(d)

FIGURE 3: Effect of ATS-E3 on the transcriptional activation of RAW264.7 cells during TLR signaling. (a) The level of iNOS mRNA in RAW264.7 cells treated with ATS-E3 $(0$ to $10 \mu \mathrm{M})$ in the presence or absence of LPS $(1 \mu \mathrm{g} / \mathrm{mL})$ for $6 \mathrm{~h}$ was determined by real-time quantitative RT-PCR. ((b) and (c)) HEK293 cells cotransfected with NF- $\kappa$ B-Luc and $\beta$-gal (as a transfection control) plasmid constructs were treated with ATS-E3 under the cotransfection conditions with FLAG-MyD88 or Myc-Syk $(1 \mu \mathrm{g} / \mathrm{mL}$ each) for $12 \mathrm{~h}$. Luciferase activity was determined using luminometery, as described in Section 2. (d) RAW264.7 cells $\left(5 \times 10^{6}\right.$ cells $\left./ \mathrm{mL}\right)$ were incubated with LPS $(1 \mu \mathrm{g} / \mathrm{mL})$ in the presence or absence of ATS-E3 for the indicated times. After preparing the nuclear fractions, the translocated levels of total transcription factors (p65, p50, and lamin A/C) were identified using immunoblotting. Relative intensity was calculated using total levels by the DNR Bio-Imaging System. ${ }^{* *} P<0.01$ compared to control group.

can block NF- $\kappa \mathrm{B}$-dependent inflammatory responses. To determine this, we first tested the inhibitory activity of this saponin on NO production, a representative NF- $\kappa \mathrm{B}$ dependent response [37], in LPS-treated RAW264.7 cells. As shown in the left panel of Figure 2(d), NO levels strongly decreased (up to $80 \%$ ) at a concentration of $10 \mu \mathrm{g} / \mathrm{mL}$ ATS-E3. However, there was no suppression of cell viability, according to the MTT assay (Figure 2(a)), implying that the inhibitory activity of ATS-E3 on NO production was not due to simple nonspecific cytotoxicity and that ATS-E3 can block NF- $\kappa$ B-mediated macrophage functions. Meanwhile, the standard compound L-NAME exhibited dose-dependent inhibitory activity up to $1 \mathrm{mM}$ (Figure 2 (d), right panel), indicating that the experimental conditions were well established, as reported previously [38].

To obtain further evidence of the suppression of NF$\kappa \mathrm{B}$-dependent inflammatory events, transcriptional activation and nuclear translocation of NF- $\kappa \mathrm{B}$ were examined by 


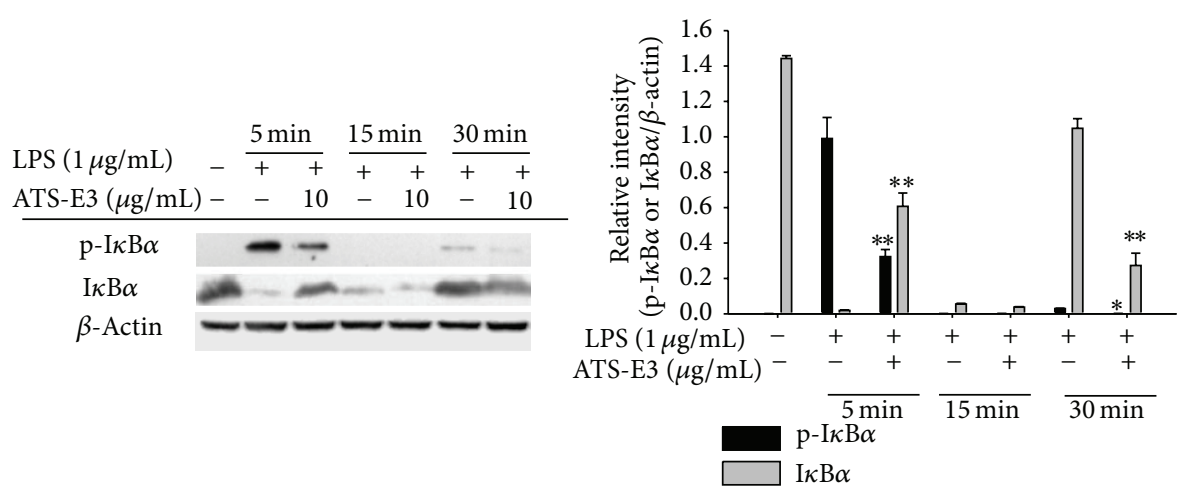

(a)
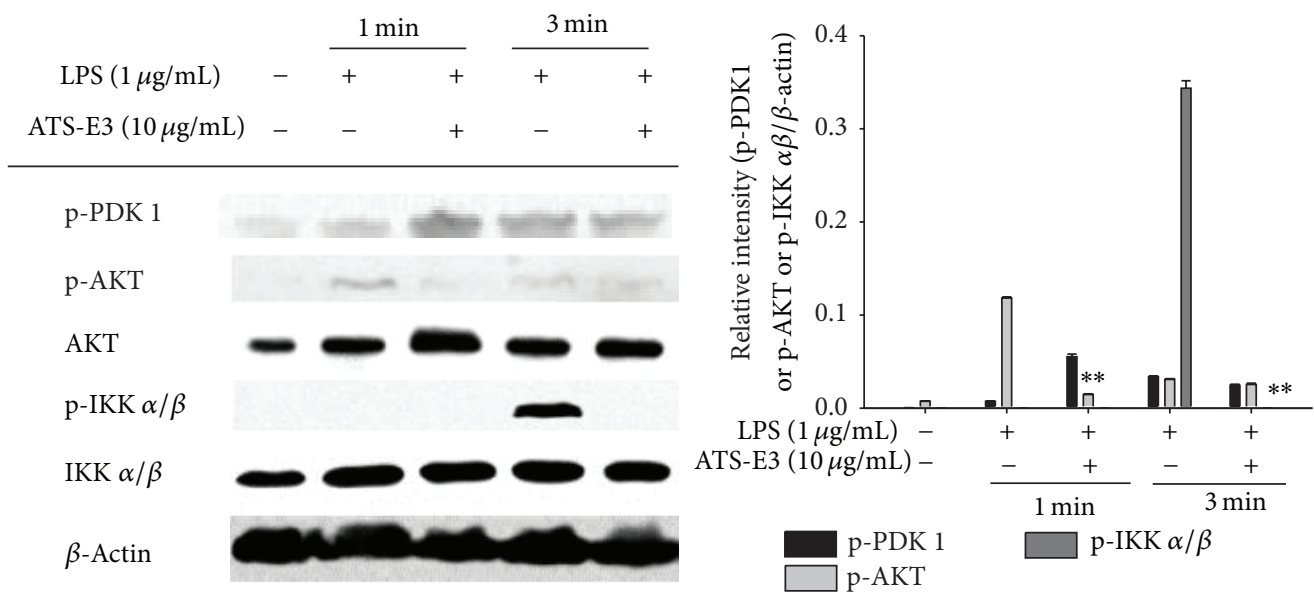

(b)

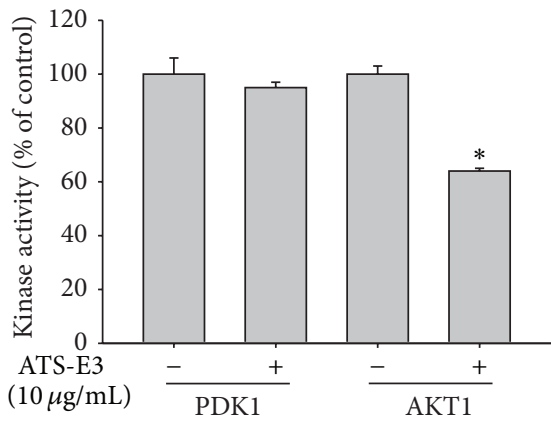

(c)

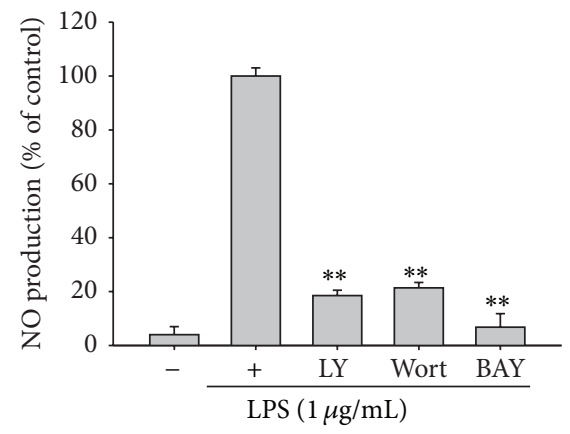

(d)

FIGURE 4: Effect of ATS-E3 on the activation of NF- $\kappa$ B upstream signaling cascades. ((a) and (b)) Total and phosphoprotein levels of PDK1, AKT, IKK $\alpha / \beta$, and $\beta$-actin in whole cell lysates of LPS-treated RAW264.7 cells were determined by immunoblotting analysis. (c) Kinase activities of PDK1 and AKT1 were determined by a direct kinase assay using purified enzymes. The value of the control, which received vehicle treatment, was set as $100 \%$ activity for each enzyme (PDK1 or AKT1). (d) NO inhibitory activities of standard compounds (BAY117082 (BAY), LY294002 (LY), and wortmannin (Wort)) were determined in RAW264.7 cells $\left(1 \times 10^{6}\right.$ cells $\left./ \mathrm{mL}\right)$ treated with LPS $(1 \mu \mathrm{g} / \mathrm{mL}) \mathrm{in}$ the presence or absence of standard compounds for $24 \mathrm{~h}$. Relative intensity was calculated using total levels by the DNR Bio-Imaging System. ${ }^{*} P<0.05$ and ${ }^{* *} P<0.01$ compared to control group.

measuring mRNA level of iNOS and performing the luciferase reporter gene assay for nuclear levels of NF- $\kappa \mathrm{B}$ subunits (p50 and p65). As depicted in Figure 3(a), the level of iNOS was remarkably diminished by $10 \mu \mathrm{g} / \mathrm{mL}$ of ATS-E3. In addition, NF- $\kappa$ B-mediated luciferase activity induced by MyD88 (Figure 3(b)) but not Syk (Figure 3(c)), a NF- $\kappa \mathrm{B}$-activating upstream tyrosine kinase [39], was dosedependently inhibited by this saponin. The nuclear translocation levels of NF- $\kappa \mathrm{B}$ subunits were also clearly reduced in response to ATS-E3 treatment $(10 \mu \mathrm{g} / \mathrm{mL})$ at 15,30 , and $60 \mathrm{~min}$ (Figure 3(d), left and right panels). These results strongly support our hypothesis regarding NF- $\kappa \mathrm{B}$ as a target 


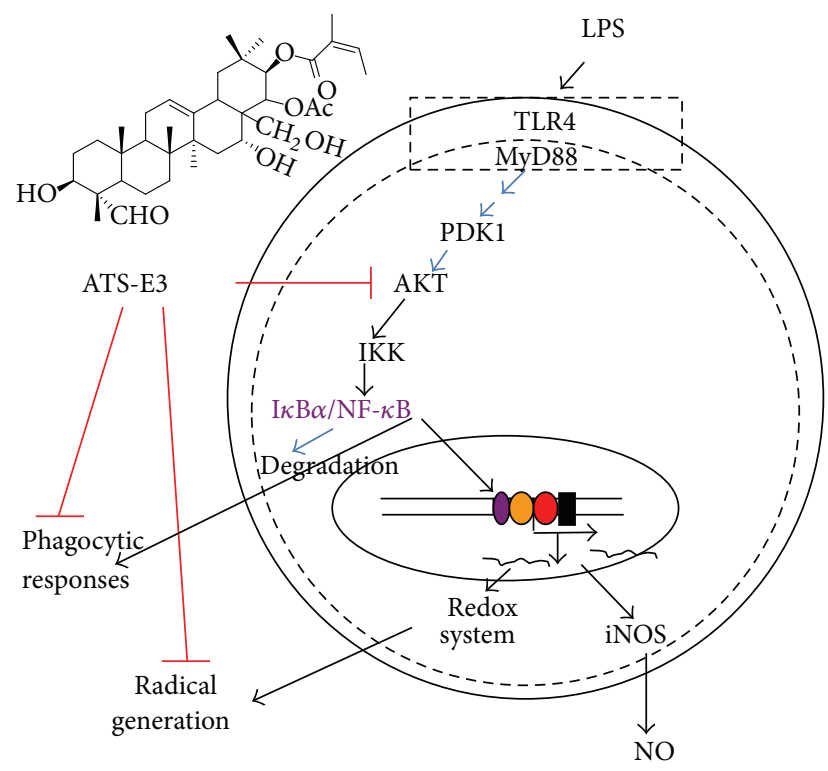

FIGURE 5: Putative inhibitory pathway of macrophage-mediated inflammatory responses by ATS-E3.

transcription factor of ATS-E3. Considering that several triterpenoid saponins have also been reported to suppress $\mathrm{NF}-\kappa \mathrm{B}$ activation $[40,41]$, it is possible that a structural unit in triterpenoid saponins contributes to the inhibition of NF$\kappa \mathrm{B}$ activation.

Finally, since the translocation of NF- $\kappa \mathrm{B}$ subunits was inhibited by ATS-E3, we next explored a potential target enzyme involved in regulating the translocation of NF$\kappa \mathrm{B}$. Interestingly, $\mathrm{I} \kappa \mathrm{B} \alpha$ phosphorylation, a critical step for translocation of NF- $\kappa \mathrm{B}$ subunits [42], was strongly reduced at 5 and $30 \mathrm{~min}$ (Figure 4(a), left and right panels), implying that the ATS-E3-targeting enzyme was activated at early time points. Therefore, we next evaluated continuous phosphorylation levels of upstream enzymes participating in $\mathrm{I} \kappa \mathrm{B} \alpha$ phosphorylation at $5 \mathrm{~min}$ by preparing whole lysates prepared from RAW264.7 cells stimulated by LPS exposure for 1 and $3 \mathrm{~min}$. As shown in Figure 4(b) (left and right panels), early phosphorylation of IKK and AKT at 1 and 3 min was clearly reduced by this compound, whereas the phosphorylation of PDK1 was not suppressed, indicating that PDK1 is a potential target of ATS-E3. To study this possibility, we conducted a kinase assay with purified PDK1 and AKT1. Although we failed to observe strong inhibitory activity by ATS-E3, we found that ATS-E3 $(10 \mu \mathrm{g} / \mathrm{mL})$ significantly suppressed AKT1 kinase activity up to $40 \%$ (Figure $4(\mathrm{c})$ ). In contrast, PDK1 activity was not reduced by this compound (Figure 4(c)), suggesting that it can directly suppress the enzyme activity of AKT, known as IKK-phosphorylating enzyme [43]. Evidence suggests that AKT plays a positive role in NF$\kappa \mathrm{B}$-mediated inflammatory responses. In the present study, overexpression of AKT resulted in IKK phosphorylation, $\mathrm{I} \kappa \mathrm{B} \alpha$ degradation, and NF- $\kappa \mathrm{B}$ translocation. Also, AKT inhibition by LY294002 and wortmannin suppressed the production of inflammatory mediators (Figure 4(d)). Indeed, we also confirmed that these compounds as well as the
IKK inhibitor BAY 11-7082 were capable of reducing the production of NO under LPS stimulation (Figure 4(d)). In addition, we recently found that Cys310 of AKT plays an important proinflammatory role [44]. Indeed, compounds that can bind to the thiol group of this cysteine residue clearly show anti-inflammatory properties by suppressing the NF- $\kappa$ B pathway [44-46]. However, the finding that ATS-E3 blocked only $40 \%$ of the AKT activity (Figure $4(\mathrm{c})$ ) indicates that there is another major target in ATS-E3 pharmacology. Therefore, future studies should include identification of ATS-E3 target proteins. Taken together, previous reports and our data strongly suggest positive regulation of inflammatory pathways, and AKT/IKK/NF- $\kappa \mathrm{B}$ regulatory loops are directly targeted by the anti-inflammatory activity of ATS-E3.

In summary, ATS-E3 strongly inhibited macrophagemediated inflammatory responses such as phagocytic uptake, ROS generation, and NO production. The inhibitory action of ATS-E3 was mediated by suppression of inflammatory pathways composed of AKT, IKK, and NF- $\kappa \mathrm{B}$, as summarized in Figure 5. Therefore, our findings strongly suggest that the novel triterpenoid saponin component ATS-E3 may contribute to the beneficial role of tea plants through its antiinflammatory activity. In view of the present data, we also propose that ATS-E3 can be further developed as the first anti-inflammatory saponin component prepared from tea plants. Therefore, our future studies will focus on providing additional pharmacological evidence to demonstrate this possibility.

\section{Conflict of Interests}

The authors report no conflict of interests. The authors alone are responsible for the content and writing of this paper.

\section{Authors' Contribution}

Woo Seok Yang, Jaeyoung Ko, and Eunji Kim contributed equally to this work.

\section{Acknowledgment}

This work was carried out with the support of the "Cooperative Research Program for Agriculture Science \& Technology Development (Project no. PJ009241)," Rural Development Administration, Republic of Korea.

\section{References}

[1] T. Yu, Y.-S. Yi, Y. Yang, J. Oh, D. Jeong, and J. Y. Cho, “The pivotal role of TBK1 in inflammatory responses mediated by macrophages," Mediators of Inflammation, vol. 2012, Article ID 979105, 8 pages, 2012.

[2] S. E. Byeon, Y.-S. Yi, J. Oh, B. C. Yoo, S. Hong, and J. Y. Cho, "The role of Src kinase in macrophage-mediated inflammatory responses," Mediators of Inflammation, vol. 2012, Article ID 512926, 18 pages, 2012.

[3] D. Laveti, M. Kumar, R. Hemalatha et al., "Anti-inflammatory treatments for chronic diseases: a review," Inflammation \& Allergy-Drug Targets, vol. 12, no. 5, pp. 349-361, 2013. 
[4] J. Frostegard, "Immune mechanisms in atherosclerosis, especially in diabetes type 2," Frontiers in Endocrinology, vol. 4, article 162, 2013.

[5] D. H. Kang and S. W. Kang, "Targeting cellular antioxidant enzymes for treating atherosclerotic vascular disease," Biomolecules and Therapeutics, vol. 21, no. 2, pp. 89-96, 2013.

[6] Y. I. Cha and H.-S. Kim, "Emerging role of sirtuins on tumorigenesis: possible link between aging and cancer," BMB Reports, vol. 46, no. 9, pp. 429-438, 2013.

[7] H.-J. Kweon and B.-C. Suh, "Acid-sensing ion channels (ASICs): therapeutic targets for neurological diseases and their regulation," BMB Reports, vol. 46, no. 6, pp. 295-304, 2013.

[8] Y. Lu, T. Umeda, A. Yagi et al., "Triterpenoid saponins from the roots of tea plant (Camellia sinensis var. assamica)," Phytochemistry, vol. 53, no. 8, pp. 941-946, 2000.

[9] X.-F. Zhang, Y.-Y. Han, G.-H. Bao et al., "A new saponin from tea seed pomace (Camellia oleifera abel) and its protective effect on PC12 cells," Molecules, vol. 17, no. 10, pp. 11721-11728, 2012.

[10] Y. Yang, W. S. Yang, T. Yu et al., "Novel anti-inflammatory function of NSC95397 by the suppression of multiple kinases," Biochemical Pharmacology, vol. 88, no. 2, pp. 201-215, 2014.

[11] T. Murakami, J. Nakamura, T. Kageura, H. Matsuda, and M. Yoshikawa, "Bioactive saponins and glycosides. XVII. Inhibitory effect on gastric emptying and accelerating effect on gastrointestinal transit of tea saponins: structures of assamsaponins F, G, H, I, and J from the seeds and leaves of the tea plant," Chemical and Pharmaceutical Bulletin, vol. 48, no. 11, pp. 1720-1725, 2000.

[12] I. Kitagawa, K. Hori, T. Motozawa, T. Murakami, and M. Yoshikawa, "Structures of new acylated oleanene-type triterpene oligoglycosides, theasaponins $\mathrm{E}_{1}$ and $\mathrm{E}_{2}$, from the seeds of tea plant, Camellia sinensis (L.) O. KUNTZE," Chemical and Pharmaceutical Bulletin, vol. 46, no. 12, pp. 1901-1906, 1998.

[13] M. Yoshikawa, T. Morikawa, N. Li, A. Nagatomo, X. Li, and H. Matsuda, "Bioactive saponins and glycosides. XXIII. Triterpene saponins with gastroprotective effect from the seeds of Camellia sinensis-theasaponins E3, E4, E5, E6, and E7," Chemical and Pharmaceutical Bulletin, vol. 53, no. 12, pp. 1559-1564, 2005.

[14] K. Duperrier, A. Eljaafari, C. Dezutter-Dambuyant et al., "Distinct subsets of dendritic cells resembling dermal DCs can be generated in vitro from monocytes, in the presence of different serum supplements," Journal of Immunological Methods, vol. 238, no. 1-2, pp. 119-131, 2000.

[15] Y. G. Lee, W. M. Lee, J. Y. Kim et al., "Src kinase-targeted anti-inflammatory activity of davallialactone from Inonotus xeranticus in lipopolysaccharide-activated RAW264.7 cells," British Journal of Pharmacology, vol. 154, no. 4, pp. 852-863, 2008.

[16] J. Y. Cho, D. A. Fox, V. Horejsi et al., “The functional interactions between CD98, $\beta 1$-integrins, and CD147 in the induction of U937 homotypic aggregation," Blood, vol. 98, no. 2, pp. 374-382, 2001.

[17] Y. G. Lee, J. Lee, and J. Y. Cho, “Cell-permeable ceramides act as novel regulators of U937 cell-cell adhesion mediated by CD29, CD98, and CD147," Immunobiology, vol. 215, no. 4, pp. 294-303, 2010.

[18] J. Y. Cho, K. U. Baik, J. H. Jung, and M. H. Park, "In vitro antiinflammatory effects of cynaropicrin, a sesquiterpene lactone, from Saussurea lappa," European Journal of Pharmacology, vol. 398, no. 3, pp. 399-407, 2000.

[19] L. C. Green, D. A. Wagner, J. Glogowski, P. L. Skipper, J. S. Wishnok, and S. R. Tannenbaum, "Analysis of nitrate, nitrite, and $\left[{ }^{15} \mathrm{~N}\right]$ nitrate in biological fluids," Analytical Biochemistry, vol. 126, no. 1, pp. 131-138, 1982.

[20] R. Pauwels, J. Balzarini, M. Baba et al., "Rapid and automated tetrazolium-based colorimetric assay for the detection of antiHIV compounds," Journal of Virological Methods, vol. 20, no. 4, pp. 309-321, 1988.

[21] Y. S. Roh, H. B. Kim, C.-W. Kang, B. S. Kim, S.-Y. Nah, and J.-H. Kim, "Neuroprotective effects of ginsenoside $\mathrm{Rg}_{3}$ against 24-OH-cholesterol-induced cytotoxicity in cortical neurons," Journal of Ginseng Research, vol. 34, no. 3, pp. 246-253, 2010.

[22] J. R. Kim, D.-R. Oh, M. H. Cha et al., "Protective effect of polygoni cuspidati radix and emodin on Vibrio vulnificus cytotoxicity and infection," Journal of Microbiology, vol. 46, no. 6, pp. 737-743, 2008.

[23] S.-I. Lim, C.-W. Cho, U.-K. Choi, and Y.-C. Kim, "Antioxidant activity and ginsenoside pattern of fermented white ginseng," Journal of Ginseng Research, vol. 34, no. 3, pp. 168-174, 2010.

[24] T. Yu, Y. J. Lee, H. M. Yang et al., "Inhibitory effect of Sanguisorba officinalis ethanol extract on $\mathrm{NO}$ and $\mathrm{PGE}_{2}$ production is mediated by suppression of NF- $\kappa \mathrm{B}$ and AP-1 activation signaling cascade," Journal of Ethnopharmacology, vol. 134, no. 1, pp. 11-17, 2011.

[25] J. Kwon, S. Kim, S. Shim, D. S. Choi, J. H. Kim, and Y. B. Kwon, "Modulation of LPS-stimulated astroglial activation by ginseng total saponins," Journal of Ginseng Research, vol. 35, no. 1, pp. 80-85, 2011.

[26] T. Shen, J. Lee, M. H. Park et al., "Ginsenoside $\mathrm{Rp}_{1}$, a ginsenoside derivative, blocks promoter activation of iNOS and Cox-2 genes by suppression of an IKK $\beta$-mediated NF- $\kappa$ B pathway in HEK293 cells," Journal of Ginseng Research, vol. 35, no. 2, pp. 200-208, 2011.

[27] S. B. Song, N. H. Tung, T. H. Quang, N. T. T. Ngan, K. E. Kim, and Y. H. Kim, "Inhibition of TNF- $\alpha$-mediated NF- $\kappa \mathrm{B}$ transcriptional activity in HepG2 cells by dammarane-type saponins from Panax ginseng leaves," Journal of Ginseng Research, vol. 36, no. 2, pp. 146-152, 2012.

[28] K. K. Jung, H. S. Lee, J. Y. Cho et al., "Inhibitory effect of curcumin on nitric oxide production from lipopolysaccharideactivated primary microglia," Life Sciences, vol. 79, no. 21, pp. 2022-2031, 2006.

[29] J. Y. Lee, Y. G. Lee, K.-J. Yang et al., “Akt Cys-310-targeted inhibition by hydroxylated benzene derivatives is tightly linked to their immunosuppressive effects," The Journal of Biological Chemistry, vol. 285, no. 13, pp. 9932-9948, 2010.

[30] T. Yu, J. Shim, Y. Yang et al., "3-(4-(tert-Octyl)phenoxy)propane-1,2-diol suppresses inflammatory responses via inhibition of multiple kinases," Biochemical Pharmacology, vol. 83, no. 11, pp. 1540-1551, 2012.

[31] M.-Y. Kim and J. Y. Cho, "20S-dihydroprotopanaxadiol, a ginsenoside derivative, boosts innate immune responses of monocytes and macrophages," Journal of Ginseng Research, vol. 37, no. 3, pp. 293-299, 2013.

[32] E. Kim, W. S. Yang, J. H. Kim et al., "Lancemaside A from Codonopsis lanceolata modulates the inflammatory responses mediated by monocytes and macrophages," Mediators of Inflammation, vol. 2014, Article ID 405158, 12 pages, 2014.

[33] A. Valavanidis, T. Vlachogianni, K. Fiotakis, and S. Loridas, "Pulmonary oxidative stress, inflammation and cancer: respirable particulate matter, fibrous dusts and ozone as major causes of lung carcinogenesis through reactive oxygen species mechanisms," International Journal of Environmental Research and Public Health, vol. 10, no. 9, pp. 3886-3907, 2013. 
[34] L. A. Tapondjou, L. B. T. Nyaa, P. Tane et al., "Cytotoxic and antioxidant triterpene saponins from Butyrospermum parkii (Sapotaceae)," Carbohydrate Research, vol. 346, no. 17, pp. 26992704, 2011.

[35] S. Li, J. Zhao, Y. Liu et al., "New triterpenoid saponins from Ilex cornuta and their protective effects against $\mathrm{H}_{2} \mathrm{O}_{2}$-induced myocardial cell injury," Journal of Agricultural and Food Chemistry, vol. 62, no. 2, pp. 488-496, 2014.

[36] Y. A. Kim, C.-S. Kong, J. I. Lee et al., "Evaluation of novel antioxidant triterpenoid saponins from the halophyte Salicornia herbacea," Bioorganic \& Medicinal Chemistry Letters, vol. 22, no. 13, pp. 4318-4322, 2012.

[37] D. H. Kim, J. H. Chung, J. S. Yoon et al., "Ginsenoside Rd inhibits the expressions of iNOS and COX-2 by suppressing NF$\kappa \mathrm{B}$ in LPS-stimulated RAW264.7 cells and mouse liver," Journal of Ginseng Research, vol. 37, no. 1, pp. 54-63, 2013.

[38] D. Jeong, Y.-S. Yi, G.-H. Sung et al., "Anti-inflammatory activities and mechanisms of Artemisia asiatica ethanol extract," Journal of Ethnopharmacology, vol. 152, no. 3, pp. 487-496, 2014.

[39] Y. S. Yi, Y. J. Son, C. Ryou, G. H. Sung, J. H. Kim, and J. Y. Cho, "Functional roles of Syk in macrophage-mediated inflammatory responses," Mediators of Inflammation, vol. 2014, Article ID 270302, 12 pages, 2014.

[40] T. H. Quang, N. T. T. Ngan, C. V. Minh et al., "Anti-inflammatory triterpenoid saponins from the stem bark of Kalopanax pictus," Journal of Natural Products, vol. 74, no. 9, pp. 1908-1915, 2011.

[41] H.-J. An, I.-T. Kim, H.-J. Park, H.-M. Kim, J.-H. Choi, and K.T. Lee, "Tormentic acid, a triterpenoid saponin, isolated from Rosa rugosa, inhibited LPS-induced iNOS, COX-2, and TNF- $\alpha$ expression through inactivation of the nuclear factor- $\kappa \mathrm{b}$ pathway in RAW 264.7 macrophages," International Immunopharmacology, vol. 11, no. 4, pp. 504-510, 2011.

[42] M. Magnani, R. Crinelli, M. Bianchi, and A. Antonelli, "The ubiquitin-dependent proteolytic system and other potential targets for the modulation of nuclear factor-kB (NF-kB)," Current Drug Targets, vol. 1, no. 4, pp. 387-399, 2000.

[43] Y. G. Lee, J. Lee, S. E. Byeon et al., "Functional role of Akt in macrophage-mediated innate immunity," Frontiers in Bioscience, vol. 16, no. 2, pp. 517-530, 2011.

[44] J. Y. Lee, Y. G. Lee, J. Lee et al., "Akt Cys-310-targeted inhibition by hydroxylated benzene derivatives is tightly linked to their immunosuppressive effects," The Journal of Biological Chemistry, vol. 285, no. 13, pp. 9932-9948, 2010.

[45] A. R. Kim, J. Y. Cho, J. Y. Lee, J. S. Choi, and H. Y. Chung, "Hydroquinone modulates reactivity of peroxynitrite and nitric oxide production," Journal of Pharmacy and Pharmacology, vol. 57, no. 4, pp. 475-481, 2005.

[46] J. Y. Lee, J. Y. Kim, Y. G. Lee et al., "Hydroquinone, a reactive metabolite of benzene, reduces macrophage-mediated immune responses," Molecules and Cells, vol. 23, no. 2, pp. 198-206, 2007. 


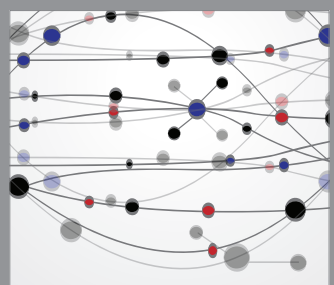

The Scientific World Journal
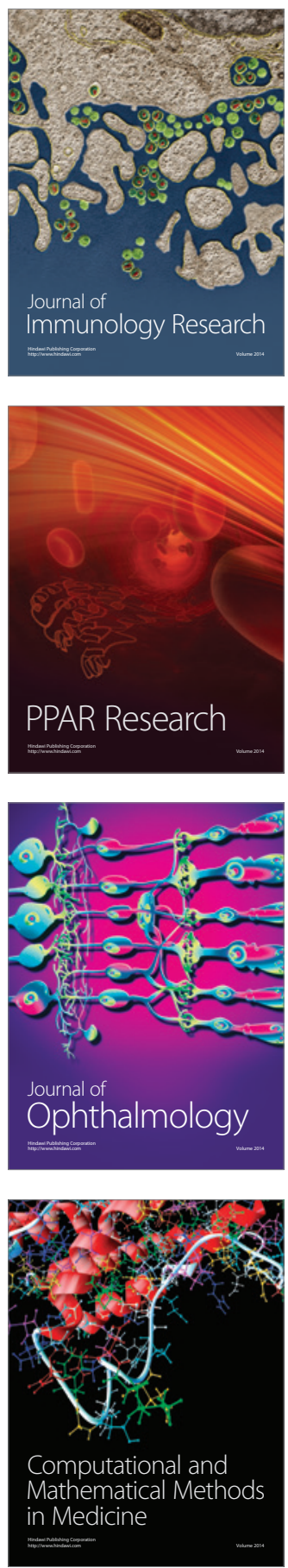

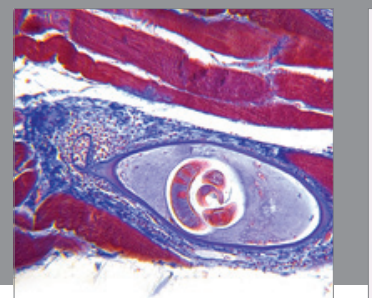

Gastroenterology

Research and Practice
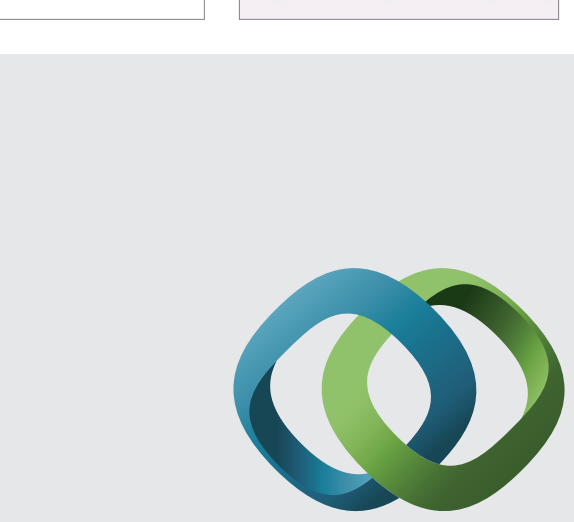

\section{Hindawi}

Submit your manuscripts at

http://www.hindawi.com
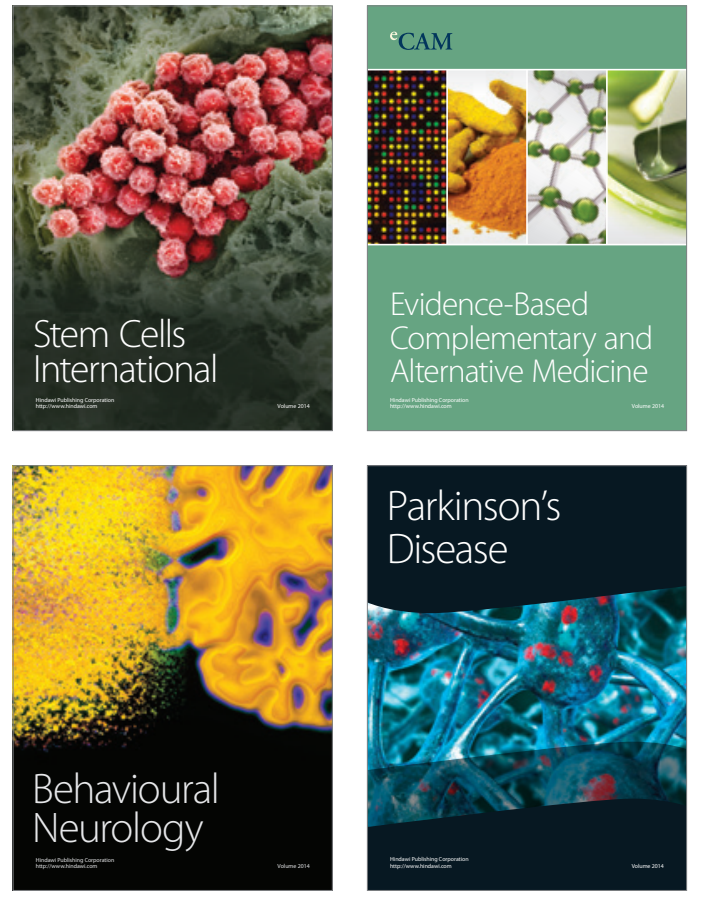
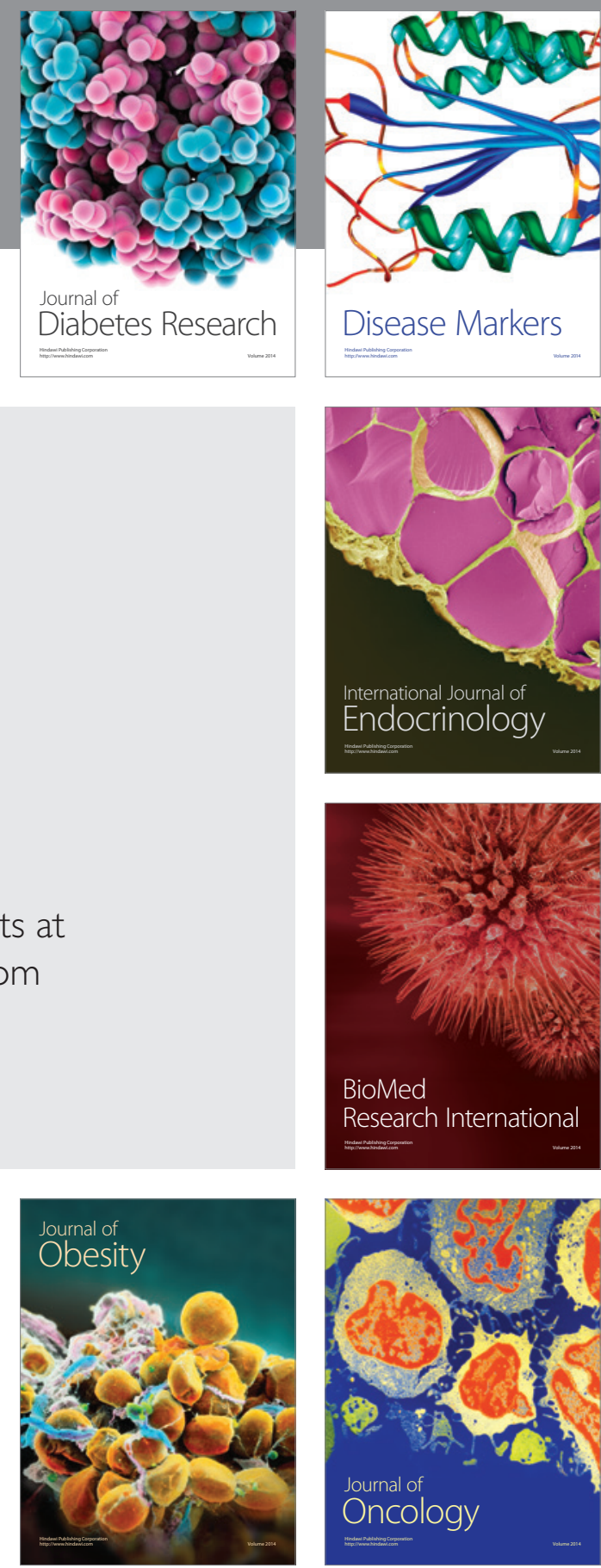

Disease Markers
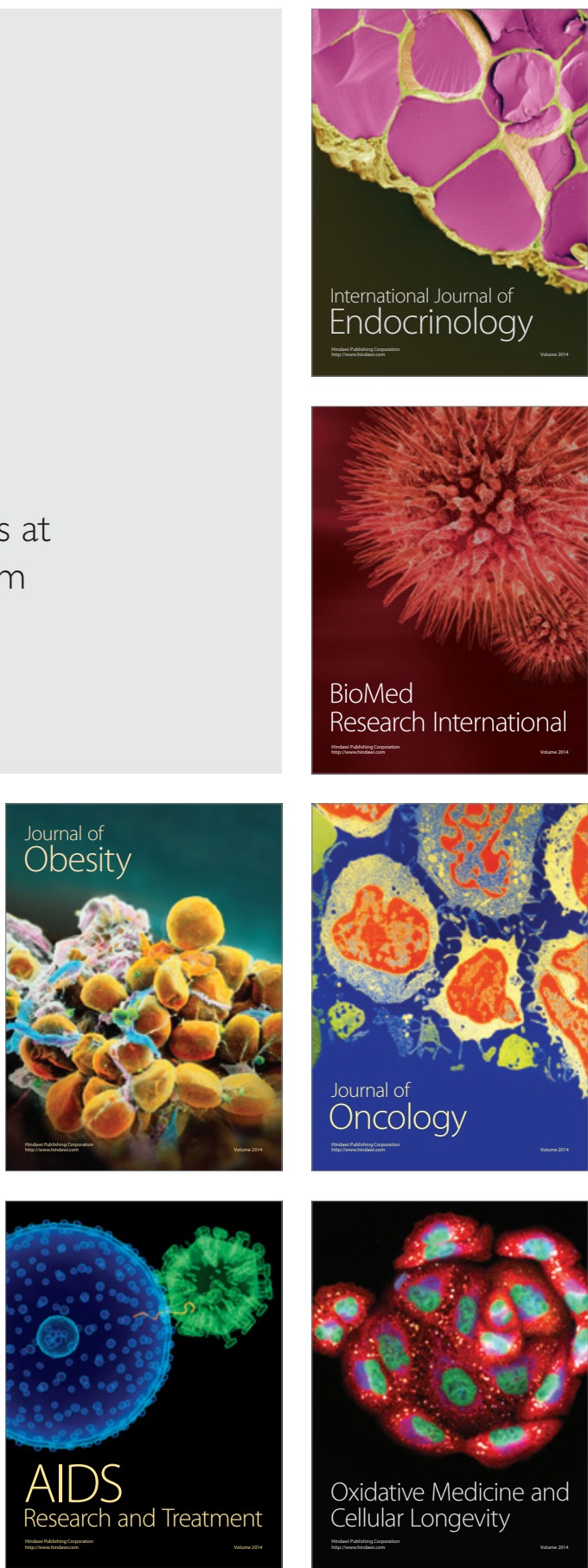